\title{
Role of prenatal magnetic resonance imaging in fetuses with isolated mild or moderate ventriculomegaly in the era of neurosonography: international multicenter study
}

\author{
The ENSO Working Group ${ }^{\#}$
}

KEYWORDS: central nervous system; fetal magnetic resonance imaging; fetal ultrasound; MRI; neurosonography; prenatal diagnosis; ventriculomegaly

\section{CONTRIBUTION}

What are the novel findings of this work?

In fetuses with a sonographic diagnosis of isolated mild or moderate ventriculomegaly (VM), the incidence of an associated fetal anomaly missed on ultrasound and detected only on fetal magnetic resonance imaging (MRI) is lower than that reported previously in the literature. The large majority of anomalies detected exclusively on MRI involve mainly migration disorders and hemorrhage, which can be difficult to detect on ultrasound and tend to have a later presentation during pregnancy.

What are the clinical implications of this work?

This is the largest study exploring the role of fetal brain MRI in detecting an associated anomaly not diagnosed on ultrasound in fetuses with mild or moderate VM. The findings of this study support the practice of MRI assessment in every fetus with a prenatal diagnosis of VM, although parents can be reassured of the low risk of an associated anomaly when VM is isolated on neurosonography.

\section{ABSTRACT \\ Objectives To assess the role of fetal magnetic reso- nance imaging (MRI) in detecting associated anomalies in fetuses presenting with mild or moderate isolated ven- triculomegaly (VM) undergoing multiplanar ultrasound evaluation of the fetal brain.}

Methods This was a multicenter, retrospective, cohort study involving 15 referral fetal medicine centers in Italy, the UK and Spain. Inclusion criteria were fetuses affected by isolated mild (ventricular atrial diameter, $10.0-11.9 \mathrm{~mm}$ ) or moderate (ventricular atrial diameter, 12.0-14.9 mm) VM on ultrasound, defined as VM with normal karyotype and no other additional central nervous system (CNS) or extra-CNS anomalies on ultrasound, undergoing detailed assessment of the fetal brain using a multiplanar approach as suggested by the International Society of Ultrasound in Obstetrics and Gynecology guidelines for the fetal neurosonogram, followed by fetal MRI. The primary outcome of the study was to report the incidence of additional CNS anomalies detected exclusively on prenatal MRI and missed on ultrasound, while the secondary aim was to estimate the incidence of additional anomalies detected exclusively after birth and missed on prenatal imaging (ultrasound and MRI). Subgroup analysis according to gestational age at MRI ( $<24$ vs $\geq 24$ weeks), laterality of VM (unilateral vs bilateral) and severity of dilatation (mild vs moderate VM) were also performed.

Results Five hundred and fifty-six fetuses with a prenatal diagnosis of isolated mild or moderate VM on ultrasound were included in the analysis. Additional structural anomalies were detected on prenatal MRI and missed on ultrasound in 5.4\% (95\% CI, 3.8-7.6\%) of cases. When considering the type of anomaly, supratentorial intracranial hemorrhage was detected on MRI in 26.7\% of fetuses, while polymicrogyria and lissencephaly were detected in $20.0 \%$ and $13.3 \%$ of cases, respectively. Hypoplasia of the corpus callosum was detected on MRI in $6.7 \%$ of cases, while dysgenesis was detected in $3.3 \%$. Fetuses with an associated anomaly detected only on MRI were more likely to have moderate than mild VM $(60.0 \%$ vs $17.7 \% ; \mathrm{P}<0.001)$, while there was no significant difference in the proportion of cases with bilateral VM between the two groups $(\mathrm{P}=0.2)$. Logistic regression analysis showed that lower maternal body mass index (adjusted odds ratio (aOR), 0.85 (95\% CI, 0.7-0.99); $\mathrm{P}=0.030)$, the presence of moderate

\footnotetext{
Correspondence to: Dr F. D’Antonio, Fetal Medicine Unit, Department of Medical and Surgical Sciences, Department of Obstetrics and Gynecology, University of Foggia, Viale L. Pinto, 71100 Foggia, Italy (e-mail: francesco.dantonio@unifg.it)

\#Participants of The ENSO Working Group are listed at end of article.
}

Accepted: 20 December 2019 
VM (aOR, 5.8 (95\% CI, 2.6-13.4); $\mathrm{P}<0.001)$ and gestational age at $M R I \geq 24$ weeks (aOR, 4.1 (95\% CI, 1.1-15.3); $\mathrm{P}=0.038$ ) were associated independently with the probability of detecting an associated anomaly on MRI. Associated anomalies were detected exclusively at birth and missed on prenatal imaging in 3.8\% of cases.

Conclusions The incidence of an associated fetal anomaly missed on ultrasound and detected only on fetal MRI in fetuses with isolated mild or moderate VM undergoing neurosonography is lower than that reported previously. The large majority of these anomalies are difficult to detect on ultrasound. The findings from this study support the practice of MRI assessment in every fetus with a prenatal diagnosis of VM, although parents can be reassured of the low risk of an associated anomaly when VM is isolated on neurosonography. Copyright (C) 2020 ISUOG. Published by John Wiley \& Sons Ltd.

\section{INTRODUCTION}

Ventriculomegaly (VM) is the most common brain anomaly diagnosed during fetal life, and encompasses a large spectrum of conditions characterized by dilatation of the lateral ventricles of the brain, typically defined as a diameter greater than $10 \mathrm{~mm}$ at the level of the atria ${ }^{1-7}$. $\mathrm{VM}$ is frequently classified according to the degree of ventricular dilatation as mild $(10.0-11.9 \mathrm{~mm})$, moderate $(12.0-14.9 \mathrm{~mm})$ or severe $(\geq 15.0 \mathrm{~mm})$, higher degrees of dilatation being associated with an increased risk of neurodevelopmental delay ${ }^{8}$.

The cause, severity and presence of associated anomalies are the major determinants in predicting the outcome of fetuses affected by VM. Thus, the main issue when evaluating a fetus with $\mathrm{VM}$ is ruling out central nervous system (CNS) and extra-CNS anomalies ${ }^{6}$. The International Society of Ultrasound in Obstetrics and Gynecology (ISUOG) recommends that every fetus presenting with isolated VM on ultrasound should undergo a thorough multiplanar ultrasound examination through axial, coronal and sagittal views of the fetal brain, possibly performed using a high-resolution transvaginal probe. Moreover, a detailed assessment of the entire fetal anatomy, including fetal echocardiography, should also be undertaken ${ }^{9}$.

Ultrasound is the primary imaging tool for assessment of the fetal brain, while fetal magnetic resonance imaging (MRI) has been shown to detect additional anomalies in $20 \%$ to $50 \%$ of cases ${ }^{10,11}$. In a recent systematic review, we found that, in fetuses diagnosed with isolated VM, the incidence of CNS anomalies detected exclusively on MRI was lower than that reported previously when a multiplanar ultrasound assessment of the fetal brain is undertaken ${ }^{12}$. However, heterogeneity among the included studies makes the results of this systematic review difficult to generalize.

The primary aim of this study was to evaluate the role of fetal MRI in detecting associated anomalies in fetuses presenting with isolated mild or moderate VM undergoing multiplanar neurosonography, and to ascertain whether the incidence of such anomalies depends on the degree and laterality of ventricular dilatation and gestational age at MRI. The secondary aim was to estimate the incidence of additional anomalies detected exclusively after birth and missed on prenatal imaging (ultrasound and MRI).

\section{METHODS}

\section{Study design and participants}

This was a multicenter, retrospective, cohort study involving 15 referral centers in Italy, the UK and Spain. The study included pregnant women who had fetal brain MRI following the diagnosis of isolated mild or moderate VM by neurosonography from January 2010 to March 2019. Only cases with postnatal imaging, or postmortem examination in cases of termination of pregnancy or fetal demise, were included. The clinical records were examined, and data were collected in a dedicated merged database.

Inclusion criteria were fetuses affected by isolated mild (ventricular atrial diameter, $10.0-11.9 \mathrm{~mm}$ ) or moderate (ventricular atrial diameter, $12.0-14.9 \mathrm{~mm}$ ) VM on ultrasound, defined as VM with no other additional CNS or extra-CNS anomalies on the scan, detailed assessment of the fetal brain via a multiplanar approach as suggested by 2007 ISUOG guidelines on the fetal neurosonogram ${ }^{9}$, detailed fetal assessment including echocardiography, normal karyotype (including chromosomal microarray, when available), negative infection screening (including cytomegalovirus and toxoplasmosis), maternal age $\geq 18$ years and gestational age $\geq 18$ weeks. Exclusion criteria were fetuses affected by severe VM (ventricular atrial diameter $\geq 15 \mathrm{~mm}$ ) on ultrasound, cases affected by chromosomal anomalies, cases affected by an additional CNS or extra-CNS anomaly at the time of the initial diagnosis, cases affected by congenital infection and ultrasound protocol unclear or unavailable.

\section{Outcomes}

The primary outcome of the study was to establish the incidence of additional CNS anomalies detected exclusively on MRI and confirmed at birth in fetuses with a prenatal diagnosis of isolated VM following dedicated neurosonography. The secondary aim was to estimate the incidence of additional anomalies detected exclusively after birth and missed on prenatal imaging (ultrasound and MRI). Subgroup analysis according to gestational age at MRI ( $<24 v s \geq 24$ weeks), laterality of VM (unilateral $v s$ bilateral) and severity of dilatation (mild $v$ s moderate VM) was also performed.

For the purpose of the analysis, additional CNS anomalies were classified into: callosal anomalies, including complete and partial agenesis of the corpus callosum, hypoplasia of the corpus callosum (HCC) and dysgenesis of the corpus callosum; septal anomalies, including all anomalies characterized by a primary defect involving the septum pellucidum with a normally 
present corpus callosum; posterior fossa anomalies, including all defects involving the cerebellar vermis and/or hemispheres; intraventricular hemorrhage; cortical anomalies, including all abnormalities associated with a primary defect in neuronal migration towards the cortical surface of the brain; periventricular heterotopia; other white matter anomalies; periventricular cysts; complex brain anomalies, including all defects characterized by the presence of multiple intracranial anomalies; and other cerebral anomalies.

We did not consider biometric variation in brain structures, such as mega cisterna magna, increased or reduced degree of ventricular dilatation or of cranial size, to be associated anomalies.

\section{Statistical analysis}

We investigated the relationship between the presence of a VM-associated structural anomaly, assessed using fetal MRI (primary outcome), and a number of maternal and fetal characteristics, including maternal age and body mass index (BMI), VM severity and laterality and gestational age at ultrasound and MRI assessment. As a secondary outcome, we investigated the relationship between the same maternal/fetal parameters and a postnatal diagnosis of a VM-associated anomaly in fetuses with isolated VM (following negative prenatal imaging).

The potential association between all recorded maternal and fetal parameters and the two outcomes was first evaluated using standard univariate analysis (using the chi-square test for categorical variables and the Kruskal-Wallis test for continuous variables). For the secondary outcome, no multivariate analysis could be performed because the number of neonates with a postnatal diagnosis of a structural anomaly was limited to 11 , and the likelihood of overfitting was too high.

With regard to the primary outcome, we investigated potential independent predictors of a fetal MRI diagnosis of a VM-associated anomaly using a two-fold approach. First, we performed random-effects logistic regression analysis, with 'hospital region' as the cluster unit. A stepwise forward process was used for model building, and the following criteria were adopted for covariate selection, with covariates being limited to four in every step of the analysis to reduce the risk of overfitting: (1) $P<0.05$ on univariate analysis; (2) clinical significance; and (3) the interval, expressed in weeks, between ultrasound and MRI examinations included a-priori as a continuous variable. To avoid multicollinearity between mean dilatation of the cerebral ventricular atrium (in $\mathrm{mm}$ ) and the severity of ventriculomegaly (classified into 'mild' or 'moderate' according to dilatation in $\mathrm{mm}$ ), only the latter covariate was included in the model as a categorical variable. Standard postestimation tests were used to check the validity of the final model, performing multicollinearity and influential observation analyses (using standardized residuals, change in Pearson and deviance chi-square) ${ }^{13,14}$.
Second, all analyses were repeated after multiple imputation with the bootstrap option for missing values $(\mathrm{m}=5 \text {, mi Stata command })^{13,14}$, as maternal BMI was not reported in $37 \%$ of cases. The results of the complete model were very similar to those of the random-effects logistic regression model, and only the results of the model without missing imputation have been shown to avoid redundancy. Statistical significance was defined as two-sided $P<0.05$ for all analyses ${ }^{15}$, which were carried out using Stata, version 13.1 (Stata Corp., College Station, TX, USA, 2013).

The study was reported following the STROBE guidelines $^{16}$.

\section{RESULTS}

\section{Characteristics of the women}

Five hundred and fifty-six fetuses with a prenatal diagnosis of isolated mild or moderate VM on ultrasound were included in the analysis. The general characteristics of the study population are shown in Table 1. Mean maternal age was $32.0 \pm 5.9$ years, while mean BMI was $24.6 \pm 4.1 \mathrm{~kg} / \mathrm{m}^{2}$. Mean gestational age at MRI was $26.7 \pm 4.4$ weeks, with $30.9 \%$ of the scans performed before 24 weeks' gestation, while $69.1 \%$ were performed at or after 24 weeks. Of the included cases, $36.5 \%$ (95\% CI, 32.6-40.4\%) (203/556) were affected by bilateral VM, while $63.5 \%$ (95\% CI, 59.4-67.4\%) (353/556) had unilateral VM. VM was mild $(10.0-11.9 \mathrm{~mm})$ in $80.0 \%(95 \% \mathrm{CI}, 76.5-83.2 \%)(445 / 556)$ of cases and moderate $(12.0-14.9 \mathrm{~mm})$ in $20.0 \%$ (95\% CI, $16.9-23.5 \%)(111 / 556)$.

\section{Synthesis of results}

Table 1 shows the results of the primary and secondary outcomes of the study. An additional structural anomaly was detected exclusively on MRI in $5.4 \%$ (95\% CI, $3.8-7.6 \%)(30 / 556)$ of cases. When considering the type of anomaly, supratentorial intracranial hemorrhage was detected exclusively on MRI in $26.7 \%$ (8/30) of cases, while polymicrogyria and lissencephaly were detected in $20.0 \%(6 / 30)$ and $13.3 \%$ (4/30) of cases, respectively. HCC was detected only on MRI in $6.7 \%$ $(2 / 30)$ of cases, while dysgenesis was detected in $3.3 \%(1 / 30)$.

The incidence of an associated anomaly detected exclusively on prenatal MRI was significantly higher in fetuses affected by moderate VM $(60.0 \%)$ than in fetuses affected by mild VM $(17.7 \%)(P<0.001)$, while there was no significant difference in the proportion of cases with bilateral VM between the two groups $(P=0.2)$. The majority $(90.0 \%)$ of fetuses with an associated anomaly had MRI performed at or after 24 weeks' gestation (Table S1).

Logistic regression analysis showed that lower maternal BMI (adjusted odds ratio (aOR), 0.85 (95\% CI, 
Table 1 Characteristics and rate of additional anomaly on magnetic resonance imaging (MRI) in 556 singleton pregnancies with prenatal sonographic diagnosis of isolated mild or moderate ventriculomegaly (VM)

\begin{tabular}{lc}
\hline Characteristic & Value \\
\hline Maternal age (years) & $32.0 \pm 5.9$ \\
Maternal body mass index $\left(\mathrm{kg} / \mathrm{m}^{2}\right)^{*}$ & $24.6 \pm 4.1$ \\
GA at prenatal ultrasound $(\mathrm{weeks})$ & $24.8 \pm 3.8$ \\
GA at prenatal MRI (weeks) & $26.7 \pm 4.4$ \\
$<24$ weeks & $172(30.9)$ \\
$\geq 24$ weeks & $384(69.1)$ \\
Interval between prenatal ultrasound and MRI (weeks) & $2.2 \pm 2.5$ \\
$\leq 2$ weeks & $420(75.5)$ \\
$3-5$ weeks & $63(11.3)$ \\
$\geq 6$ weeks & $73(13.1)$ \\
Bilateral VM & $203(36.5)$ \\
Severity of VM & \\
Mild & $445(80.0)$ \\
Moderate & $111(20.0)$ \\
Ventricular atrial dilatation (mm) in: & \\
All fetuses & $11.6 \pm 1.3$ \\
Mild-VM group & $11.1 \pm 0.7$ \\
Moderate-VM group & $13.8 \pm 0.8$ \\
Dilatation of contralateral ventricular atrium (mm) & $11.8 \pm 1.4$ \\
Additional anomaly on prenatal MRI & $30(5.4)$ \\
Hemorrhage & $8 / 30(26.7)$ \\
Polymicrogyria & $6 / 30(20.0)$ \\
Lissencephaly & $4 / 30(13.3)$ \\
Corpus callosum hypoplasia & $2 / 30(6.7)$ \\
Periventricular heterotopia & $2 / 30(6.7)$ \\
Other & $8 / 30(26.7)$ \\
Additional anomaly on postnatal MRI $\neq$ & $11 / 289(3.8)$ \\
\hline Data & \\
\hline
\end{tabular}

Data are given as mean $\pm \mathrm{SD}, n(\%)$ or $n / \mathrm{N}(\%)$. "Data available for 349 cases. †Based on 203 fetuses with bilateral VM. ‡Analysis restricted to 289 neonates without prenatal diagnosis of structural anomaly and that had postnatal MRI examination available.

$0.7-0.99) ; P=0.030)$, the presence of moderate VM (aOR, 5.8 (95\% CI, 2.6-13.4); $P<0.001$ ) and gestational age at MRI at least 24 weeks (aOR, 4.1 (95\% CI, $1.1-15.3) ; P=0.038$ ) were associated independently with the probability of detecting an associated anomaly on prenatal MRI. The interval in weeks between ultrasound and MRI assessment was not associated significantly with an anomaly on prenatal MRI (aOR, 1.00 (95\% CI, 0.84-1.21); $P=0.919)$.

After birth, 3.8\% (11/289) of cases with isolated VM confirmed on prenatal MRI had an associated anomaly detected exclusively on postnatal imaging (cranial ultrasound and/or postnatal MRI). Mean ventricular atrial dilatation was significantly higher in fetuses with a postnatal diagnosis of an associated anomaly than in those that had isolated VM confirmed on postnatal imaging $(13.0 \pm 1.5 \mathrm{~mm}$ vs $11.5 \pm 1.3 \mathrm{~mm}$; $P=0002)$. Furthermore, fetuses with a postnatal diagnosis of an associated anomaly were more likely to be affected by bilateral $(81.8 \%$ vs $50.0 \%$; $P=0.04)$ and moderate $(63.6 \%$ vs $18.7 \% ; P<0.001) \mathrm{VM}$ than were those with isolated VM confirmed after birth (Table S2).

\section{DISCUSSION}

\section{Summary of main findings}

The findings of this study show that, in fetuses with a prenatal diagnosis of isolated mild or moderate VM examined using multiplanar neurosonography, the rate of an additional structural anomaly detected exclusively on fetal brain MRI was $5.4 \%$. The most common types of anomaly were supratentorial intracranial hemorrhage and neuronal migration disorders. Factors associated independently with a higher incidence of an additional finding detected exclusively on fetal MRI were gestational age at $\mathrm{MRI} \geq 24$ weeks, moderate ventricular atrial dilatation and lower maternal BMI. The rate of an associated anomaly detected exclusively after birth and missed on prenatal imaging was $3.8 \%$.

\section{Strengths and limitations}

The large sample size, inclusion of cases examined using a multiplanar approach as proposed by ISUOG guidelines on fetal neurosonography and stratification of the analyses according to the degree and laterality of ventricular atrial dilatation represent the main strengths of this study. The retrospective non-randomized design represents the main limitation of the study, and led to challenges in obtaining all imaging details for all fetuses in the participating centers, with some cases of incomplete follow-up and some missing data, mostly related to postnatal MRI or ultrasound and karyotyping. Furthermore, although $75.5 \%$ of fetuses underwent MRI 2 weeks or less after the neurosonogram, $24.5 \%$ underwent MRI after 3 to more than 6 weeks after ultrasound; therefore, it is likely that a prolonged interval between ultrasound and MRI may have influenced our results. Finally, the present study included cases undergoing neurosonography performed in each participating center, without taking into account its feasibility according to different maternal and fetal characteristics.

\section{Implications for research and clinical practice}

Isolated VM represents a considerable diagnostic dilemma, as it can be an apparently benign finding, but it can also be associated with chromosomal abnormalities, congenital infections, cerebral vascular accidents or hemorrhage and other fetal cerebral and extracerebral abnormalities ${ }^{5-7}$. Even when isolated, VM has been reported to increase the risk of neurodevelopmental delay in childhood and adolescence. The prevalence of neurodevelopmental disorders in fetuses with both unilateral and bilateral mild VM has been reported to be only slightly higher than that in the general population ${ }^{17-19}$. Conversely, the rate of neurodevelopmental delay is higher in cases of VM associated with additional CNS anomalies and in cases of severe ventricular atrial dilatation $^{20-22}$

The ISUOG guidelines on sonographic examination of the fetal CNS suggest that a multiplanar assessment of the 
fetal head should be always performed when suspicion of a brain anomaly is raised at the basic ultrasound examination ${ }^{9}$. Furthermore, in a recent consult series on mild VM, the Society for Maternal-Fetal Medicine stated that MRI may be considered in cases of mild or moderate fetal VM, although it may be of less value if the woman has undergone detailed ultrasound assessment by an individual with specific experience and expertise in sonographic imaging of the fetal brain ${ }^{8}$.

MRI is the imaging technique of choice for analyzing brain anomalies postnatally. MRI has better regional resolution than does ultrasound, thus it should, theoretically, be better than ultrasound at detecting abnormalities of cortical development. Based on these findings, current practice suggests a prenatal MRI examination in the late second or early third trimester of pregnancy, although there is no complete agreement among different researchers regarding the need for and timing of the MRI examination. However, the large majority of published studies on MRI do not specify which type of ultrasound imaging protocol was adopted to assess the fetal brain, but this is fundamental, as most CNS anomalies cannot be detected easily on the standard axial plane of the fetal brain ${ }^{12,23-29}$.

In 2017, the results of a large, prospective, multicenter study (the MERIDIAN study) involving 16 centers across the UK and designed to evaluate the diagnostic and clinical role of fetal MRI in fetuses with suspicion or diagnosis of a CNS anomaly on a previous ultrasound examination were published $^{11}$. This study showed much greater diagnostic accuracy of MRI compared with ultrasound $193 \%$ vs $68 \%$ ), with additional findings detected exclusively on MRI in $49 \%$ of cases overall and in up to $19.4 \%$ when focusing on the subgroup of fetuses with mild or moderate $\mathrm{VM}^{23}$. Of note, the rate of associated callosal anomalies detected exclusively on MRI was lower in our cohort than that in the MERIDIAN study $(10 \%$ vs $55 \%$ of cases of failed commissuration $)^{23}$.

In the present study, the large majority of anomalies detected exclusively on prenatal MRI included neuronal migration (lissencephaly, heterotopia) or acquired anomalies (e.g. hemorrhage) that can be difficult to diagnose on ultrasound ${ }^{30-34}$. In this scenario, fetal MRI should always be performed in order to rule out associated anomalies that can be potentially missed on ultrasound. Nevertheless, parents should be reassured regarding the low risk of such additional anomalies.

In the present study, MRI performed at or after 24 weeks' gestation was an independent risk factor for an additional anomaly detected exclusively on MRI. This finding might appear quite intuitive, as some abnormalities, such as malformations of cortical development, migration disorders and hemorrhage become evident only later during pregnancy. Not surprisingly, the most frequent types of anomaly detected only on MRI in this study were hemorrhage and migration disorders, which are anomalies presenting mostly after the second trimester of pregnancy ${ }^{35}$. However, some authors have suggested that early MRI (before 24 weeks) may be reliable and has similar accuracy to MRI performed later in gestation ${ }^{11,12}$, with the advantage of an early diagnosis that can allow parents the option of earlier management, especially in countries in which termination of pregnancy is not legal beyond the second trimester.

\section{Conclusions}

The rate of an associated fetal anomaly missed on ultrasound and detected only on MRI in fetuses with mild or moderate VM is lower than that reported previously in the published literature when a multiplanar ultrasound examination of the fetal brain is performed. The large majority of anomalies detected exclusively on MRI involve mainly migration disorders and hemorrhage, which cannot be detected easily on ultrasound, thus highlighting the need for an MRI examination in fetuses with a prenatal diagnosis of VM undergoing neurosonography. Future research investigating the prenatal diagnosis of isolated VM should aim for a multicenter prospective approach, mainly to establish the optimal timing and frequency of MRI examinations.

\section{The European NeuroSOnography (ENSO) Working Group}

Daniele Di Mascio*, Department of Maternal and Child Health and Urological Sciences, Sapienza University of Rome, Rome, Italy; Division of Maternal-Fetal Medicine, Department of Obstetrics and Gynecology, Sidney Kimmel Medical College of Thomas Jefferson University, Philadelphia, PA, USA

Asma Khalil, Fetal Medicine Unit, St George's University Hospitals NHS Foundation Trust, University of London, London, UK; Vascular Biology Research Centre, Molecular and Clinical Sciences Research Institute, St George's University of London, London, UK

Basky Thilaganathan, Fetal Medicine Unit, St George's University Hospitals NHS Foundation Trust, University of London, London, UK; Vascular Biology Research Centre, Molecular and Clinical Sciences Research Institute, St George's University of London, London, UK

Giuseppe Rizzo, Division of Maternal and Fetal Medicine, Ospedale Cristo Re, University of Rome Tor Vergata, Rome, Italy; Department of Obstetrics and Gynecology, The First I.M. Sechenov Moscow State Medical University, Moscow, Russia

Danilo Buca, Department of Obstetrics and Gynecology, University of Chieti, Chieti, Italy

Marco Liberati, Department of Obstetrics and Gynecology, University of Chieti, Chieti, Italy

Claudio Celentano, Department of Obstetrics and Gynecology, University of Chieti, Chieti, Italy

Karen Melchiorre, Department of Obstetrics and Gynecology, Santo Spirito Hospital, Pescara, Italy

Massimo Caulo, Department of Neuroscience, Imaging and Clinical Sciences, Institute for Advanced Biomedi- 
cal Technologies, “G. D’Annunzio" University of Chieti, Chieti, Italy

Gianluigi Pilu, Unit of Obstetrics, Department of Medical and Surgical Sciences, University of Bologna, Bologna, Italy

Ginevra Salsi, Unit of Obstetrics, Department of Medical and Surgical Sciences, University of Bologna, Bologna, Italy

Francesco Toni, IRCCS Istituto delle Scienze Neurologiche UOC Neuroradiologia, Bologna, Italy

Tamara Stampalija, Unit of Fetal Medicine and Prenatal Diagnosis, Institute for Mother and Child Health IRCCS Burlo Garofolo, Trieste, Italy; Department of Medicine, Surgery and Health Sciences, University of Trieste, Trieste, Italy

Ilaria Fantasia, Unit of Fetal Medicine and Prenatal Diagnosis, Institute for Mother and Child Health IRCCS Burlo Garofolo, Trieste, Italy

Giulia Luise, Unit of Fetal Medicine and Prenatal Diagnosis, Institute for Mother and Child Health IRCCS Burlo Garofolo, Trieste, Italy

Massimo Gregori, Unit of Paediatric Radiology, Institute for Maternal and Child Health IRCCS Burlo Garofolo, Trieste, Italy

Paolo Volpe, Fetal Medicine Unit, Di Venere and Sarcone Hospitals, Bari, Italy

Claudiana Olivieri, Fetal Medicine Unit, Di Venere and Sarcone Hospitals, Bari, Italy

Antonella Giancotti, Department of Maternal and Child Health and Urological Sciences, Sapienza University of Rome, Rome, Italy

Valentina D'Ambrosio, Department of Maternal and Child Health and Urological Sciences, Sapienza University of Rome, Rome, Italy

Roberto Brunelli, Department of Maternal and Child Health and Urological Sciences, Sapienza University of Rome, Rome, Italy

Pierluigi Benedetti Panici, Department of Maternal and Child Health and Urological Sciences, Sapienza University of Rome, Rome, Italy

Lucia Manganaro, Department of Radiology, AnatomoPathology and Oncology, Sapienza University of Rome, Rome, Italy

Amanda Antonelli, Department of Radiology, AnatomoPathology and Oncology, Sapienza University of Rome, Rome, Italy

Giada Ercolani, Department of Radiology, AnatomoPathology and Oncology, Sapienza University of Rome, Rome, Italy

Lucia Pasquini, Fetal Medicine Unit, Department for Women and Children Health, AOU Careggi, Florence, Italy

Giulia Masini, Fetal Medicine Unit, Department for Women and Children Health, AOU Careggi, Florence, Italy

Marco Di Maurizio, UOC Radiodiagnostica, AOU Meyer, Florence, Italy

Christoph Lees, Department of Surgery and Cancer, Institute of Reproductive and Developmental Biology,
Imperial College London, London, UK; Centre for Fetal Care, Queen Charlotte's and Chelsea Hospital, Imperial College Healthcare NHS Trust, London, UK

Gabriella Bracalente, Fetal Medicine Unit, Department of Obstetrics and Gynecology, Ospadele Cà Foncello, Treviso, Italy

José Morales-Roselló, Servicio de Obstetricia, Hospital Universitario y Politécnico La Fe, Valencia, Spain; Departamento de Pediatría Obstetricia y Ginecología, Universitat de Valencia, Valencia, Spain

Gabriela Loscalzo, Servicio de Obstetricia, Hospital Universitario y Politícnico La Fe, Valencia, Spain

Gabriele Saccone, Department of Neuroscience, Reproductive Sciences and Dentistry, School of Medicine, University of Naples Federico II, Naples, Italy

Luigi Carbone, Department of Neuroscience, Reproductive Sciences and Dentistry, School of Medicine, University of Naples Federico II, Naples, Italy

Laura Sarno, Department of Neuroscience, Reproductive Sciences and Dentistry, School of Medicine, University of Naples Federico II, Naples, Italy

Giuseppe Maria Maruotti, Department of Neuroscience, Reproductive Sciences and Dentistry, School of Medicine, University of Naples Federico II, Naples, Italy

Fulvio Zullo, Department of Neuroscience, Reproductive Sciences and Dentistry, School of Medicine, University of Naples Federico II, Naples, Italy

Tullio Ghi, Department of Medicine and Surgery, Unit of Surgical Sciences, Obstetrics and Gynecology, University of Parma, Parma, Italy

Tiziana Frusca, Department of Medicine and Surgery, Unit of Surgical Sciences, Obstetrics and Gynecology, University of Parma, Parma, Italy

Andrea Dall'Asta, Department of Surgery and Cancer, Institute of Reproductive and Developmental Biology, Imperial College London, London, UK; Centre for Fetal Care, Queen Charlotte's and Chelsea Hospital, Imperial College Healthcare NHS Trust, London, UK; Department of Medicine and Surgery, Unit of Surgical Sciences, Obstetrics and Gynecology, University of Parma, Parma, Italy

Nicola Volpe, Department of Medicine and Surgery, Unit of Surgical Sciences, Obstetrics and Gynecology, University of Parma, Parma, Italy

Francesca Ormitti, Department of Radiology, Azienda Ospedaliera Universitaria di Parma, Parma, Italy

Silvia Buongiorno, Servicio de Obstetricia, Hospital Universitario y Politécnico La Fe, Valencia, Spain; Departamento de Pediatría Obstetricia y Ginecología, Universidad de Valencia, Valencia, Spain; Department of "Scienze della Salute della Donna, del Bambino e di Sanitá Pubblica", Fondazione Policlinico Universitario A. Gemelli IRCCS, Rome, Italy

Marco De Santis, Department of "Scienze della Salute della Donna, del Bambino e di Sanitá Pubblica", Fondazione Policlinico Universitario A. Gemelli IRCCS, Rome, Italy 
Luisa D'Oria, Department of "Scienze della Salute della Donna, del Bambino e di Sanitá Pubblica”, Fondazione Policlinico Universitario A. Gemelli IRCCS, Rome, Italy

Antonio Lanzone, Department of "Scienze della Salute della Donna, del Bambino e di Sanità Pubblica", Fondazione Policlinico Universitario A. Gemelli IRCCS, Rome, Italy

Federico Prefumo, Division of Obstetrics and Gynecology, Department of Clinical and Experimental Sciences, University of Brescia, Brescia, Italy; Division of Obstetrics and Gynecology, ASST Spedali Civili, Brescia, Italy

Lorenzo Pinelli, Neuroradiology Unit, Paediatric Neuroradiology Section, ASST Spedali Civili, Brescia, Italy

Emma Bertucci, Department of Medical and Surgical Sciences for Mothers, Children and Adults, University of Modena and Reggio Emilia, AOU Policlinico, Modena, Italy

Filomena Giulia Sileo, Department of Medical and Surgical Sciences for Mothers, Children and Adults, University of Modena and Reggio Emilia, AOU Policlinico, Modena, Italy

Maria Elena Flacco, Department of Medical Sciences, University of Ferrara, Ferrara, Italy

Lamberto Manzoli, Department of Medical Sciences, University of Ferrara, Ferrara, Italy

Ilaria Giangiordano, Department of Child and Adolescent Neuropsychiatry, Local Health Unit of Avezzano-Sulmona-L'Aquila, Sulmona, Italy

Luciana Mastricci, Fetal Medicine Unit, Department of Medical and Surgical Sciences, University of Foggia, Foggia, Italy

Gabriella Meccariello, Fetal Medicine Unit, Department of Medical and Surgical Sciences, University of Foggia, Foggia, Italy

Lorenzo Vasciaveo, Fetal Medicine Unit, Department of Medical and Surgical Sciences, University of Foggia, Foggia, Italy

Luigi Nappi, Fetal Medicine Unit, Department of Medical and Surgical Sciences, University of Foggia, Foggia, Italy

Alessandra Familiari, Department of Obstetrics and Gynecology, Fondazione IRCCS Ca' Granda Ospedale Maggiore Policlinico, Milan, Italy

Giovanni Scambia, Department of "Scienze della Salute della Donna, del Bambino e di Sanità Pubblica" Fondazione Policlinico Universitario A. Gemelli IRCCS, Rome, Italy

Vincenzo Berghella, Division of Maternal-Fetal Medicine, Department of Obstetrics and Gynecology, Sidney Kimmel Medical College of Thomas Jefferson University, Philadelphia, PA, USA

Francesco D'Antonio†, Fetal Medicine Unit, Department of Medical and Surgical Sciences, University of Foggia, Foggia, Italy

*First author.

†Senior author.

\section{REFERENCES}

1. Achiron R, Schimmel M, Achiron A, Mashiach S. Fetal mild idiopathic lateral ventriculomegaly: is there a correlation with fetal trisomy? Ultrasound Obstet Gynecol 1993; 3: 89-92.

2. Alagappan R, Browing PD, Laorr A, McGahan JP. Distal lateral ventricular atrium: reevaluation of normal range. Radiology 1994; 193: 405-408.

3. Nomura ML, Barini R, De Andrade C, Milanez H, Simoni RZ, Peralta CF, Machado IN, Zambelli H, Maio KT. Congenital hydrocephalus: gestational age and neonatal outcomes. Arch Gynecol Obstet 2010; 282: 607-611.

4. Garel C, Luton D, Oury JF, Gressens P. Ventricular dilatations. Childs Nerv Syst 2003; 19: 517-523

5. Signorelli M, Tiberti A, Valsariati D, Molin E, Cerri V, Groli C, Bianchi UA. Width of fetal lateral ventricular atrium between 10 and $12 \mathrm{~mm}$ : a simple variation of the norm? Ultrasound Obstet Gynecol 2004; 23: 14-18.

6. Melchiorre K, Bhide A, Gika AD, Pilu G, Papageorghiou AT. Counseling in isolated mild fetal ventriculomegaly. Ultrasound Obstet Gynecol 2009; 34 212-224.

7. Shizuo OI. Hydrocepahlus research update-controversies in definition and classification of hydrocephalus. Neurol Med Chir (Tokyo) 2010; 50: 859-869.

8. Society for Maternal-Fetal Medicine (SMFM); Fox NS, Monteagudo A, Kuller JA, Craigo S, Norton ME. Mild fetal ventriculomegaly: diagnosis, evaluation, and management. Am J Obstet Gynecol 2018; 219: B2-B9.

9. International Society of Ultrasound in Obstetrics and Gynecology Education Committee. Sonographic examination of the fetal central nervous system: guidelines for performing the 'basic examination' and the 'fetal neurosonogram'. Ultrasound Obstet Gynecol 2007; 29: 109-116.

10. Rossi AC, Prefumo F. Additional value of fetal magnetic resonance imaging in the prenatal diagnosis of central nervous system anomalies: a systematic review of the literature. Ultrasound Obstet Gynecol 2014; 44: 388-393.

11. Griffiths PD, Bradburn M, Campbell MJ, Cooper CL, Graham R, Jarvis D, Kilby MD, Mason G, Mooney C, Robson SC, Wailoo A; MERIDIAN collaborative group. Use of MRI in the diagnosis of fetal brain abnormalities in utero (MERIDIAN): a multicentre, prospective cohort study. Lancet 2017; 389: 538-546.

12. Di Mascio D, Sileo FG, Khalil A, Rizzo G, Persico N, Brunelli R, Giancotti A, Panici PB, Acharya G, D’Antonio F. Role of magnetic resonance imaging in fetuses with mild or moderate ventriculomegaly in the era of fetal neurosonography: systematic review and meta-analysis. Ultrasound Obstet Gynecol 2019; 54 $164-171$.

13. Pizzi C, Costa GM, Santarella L, Flacco ME, Capasso L, Bert F, Manzoli L. Depression symptoms and the progression of carotid intima-media thickness: A 5-year follow-up study. Atherosclerosis 2014; 233: 530-536.

14. White IR, Royston P, Wood AM. Multiple imputation using chained equations Issues and guidance for practice. Stat Med 2011; 30: 377-399.

15. McNamee R. Regression modelling and other methods to control confounding. Occup Environ Med 2005; 62: 500-506.

16. Von Elm E, Altman DG, Egger M, Pocock SJ, Gøtzsche PC, Vandenbroucke JP; STROBE Initiative. The Strengthening the Reporting of Observational Studies in Epidemiology (STROBE) statement: guidelines for reporting observational studies. Lancet 2007; 370: 1453-1457.

17. Scala C, Familiari A, Pinas A, Papageorghiou AT, Bhide A, Thilaganathan B, Khalil A. Perinatal and long-term outcome in fetuses diagnosed with isolated unilateral ventriculomegaly: systematic review and meta-analysis. Ultrasound Obstet Gynecol 2017; 49: 450-459.

18. Pagani G, Thilaganathan B, Prefumo F. Neurodevelopmental outcome in isolated mild fetal ventriculomegaly: systematic review and meta-analysis. Ultrasound Obstet Gynecol 2014; 44: 254-260.

19. Thorup E, Jensen LN, Bak GS, Ekelund CK, Greisen G, Jørgensen DS, Hellmuth SG, Wulff C, Petersen OB, Pedersen LH, Tabor A. Neurodevelopmental disorder in children believed to have isolated mild ventriculomegaly prenatally. Ultrasound Obstet Gynecol 2019; 54: 182-189.

20. Weichtert J, Hartge D, Krapp M, Germer U, Gembruch U, Axt-Fliedner R. Prevalence, characteristics and perinatal outcome of fetal ventriculomegaly in 29,000 pregnancies followed at a single institution. Fetal Diagn Ther 2010; 27: $142-148$.

21. Carta S, Kaelin Agten A, Belcaro C, Bhide A. Outcome of fetuses with prenatal diagnosis of isolated severe bilateral ventriculomegaly: systematic review and meta-analysis. Ultrasound Obstet Gynecol 2018: 52: 165-173.

22. Dall'Asta A, van Oostrum NHM, Basheer SN, Paramasivam G, Ghi T, Galli L, Groenenberg IA, Tangi A, Accorsi P, Echevarria M, Angeles Rodríguez Perez M, Albaiges Baiget G, Prefumo F, Frusca T, Go AT, Lees CC. Etiology and Prognosis of Severe Ventriculomegaly Diagnosed at Late Gestation. Ultraschall Med 2018; 39 : $675-689$.

23. Griffiths PD, Brackley K, Bradburn M, Connolly DJ, Gawne-Cain ML, Griffiths DI, Kilby MD, Mandefield L, Mooney C, Robson SC, Vollmer B, Mason G. Anatomical subgroup analysis of the MERIDIAN cohort: ventriculomegaly. Ultrasound Obstet Gynecol 2017; 50: 736-744.

24. Griffiths P, Reeves M, Morris J, Mason G, Russell S, Paley M, Whitby E. A prospective study of fetuses with isolated ventriculomegaly investigated by antenatal sonography and in utero MR imaging. Am J Neuroradiol 2010; 31: $106-111$.

25. Lavongtheung A, Jedraszak G, Naepels P, Tourneux P, Gondry-Jouet C, Le Moing AG, Gondry J, Chevreau J. Should isolated fetal ventriculomegaly measured below $12 \mathrm{~mm}$ be viewed as a variant of the norm? Results of a 5-year experience in a prenatal referral center. J Matern Fetal Neonatal Med 2018; 31: $2325-2331$. 
26. Mehlhorn AJ, Morin CE, Wong-You-Cheong JJ, Contag SA. Mild fetal cerebral ventriculomegaly: prevalence, characteristics, and utility of ancillary testing in cases presenting to a tertiary referral center. Prenat Diagn 2017; 37: 647-657.

27. Kandula T, Fahey M, Chalmers R, Edwards A, Shekleton P, Teoh M, Clark J, Goergen SK. Isolated ventriculomegaly on prenatal ultrasound: what does fetal MRI add? J Med Imaging Radiat Oncol 2015; 59: 154-162.

28. Morris JE, Rickard S, Paley MNJ, Griffiths PD, Rigby A, Whitby EH. The value of in-utero magnetic resonance imaging in ultrasound diagnosed foetal isolated cerebral ventriculomegaly. Clin Radiol 2007; 62: 140-144.

29. Gezer NS, Gezer C, Ekin A, Yesilirmak DC, Solmaz U, Dogan A, Guleryuz H Obstetric and neurodevelopmental outcome in fetal cerebral ventriculomegaly. Clin Exp Obstet Gynecol 2016; 43: 490-494.

30. Dhouib A, Blondiaux E, Moutard ML, Billette de Villemeur T, Chalard F, Jouannic JM, Ducou le Pointe H, Garel C. Correlation between pre- and postnatal cerebral magnetic resonance imaging. Ultrasound Obstet Gynecol 2011; 38 170-178.
31. Pugash D, Hendson G, Dunham CP, Dewar K, Money DM, Prayer D. Sonographic assessment of normal and abnormal patterns of fetal cerebral lamination. Ultrasound Obstet Gynecol 2012; 40: 642-651.

32. Greco P, Resta M, Vimercati A, Dicuonzo F, Loverro G, Vicino M, Selvaggi L. Antenatal diagnosis of isolated lissencephaly by ultrasound and magnetic resonance imaging. Ultrasound Obstet Gynecol 1998; 12: 276-279.

33. Blondiaux E, Sileo C, Nahama-Allouche C, Moutard ML, Gelot A, Jouannic JM, Ducou le Pointe H, Garel C. Periventricular nodular heterotopia on prenatal ultrasound and magnetic resonance imaging. Ultrasound Obstet Gynecol 2013 42: 149-155.

34. Ghi T, Simonazzi G, Perolo A, Savelli L, Sandri F, Bernardi B, Santini D, Bovicelli I, Pilu G. Outcome of antenatally diagnosed intracranial hemorrhage: case series and review of the literature. Ultrasound Obstet Gynecol 2003; 22: 121-130.

35. Malinger G, Lerman-Sagie T, Watemberg N, Rotmensch S, Lev D, Glezerman M. A normal second-trimester ultrasound does not exclude intracranial structural pathology. Ultrasound Obstet Gynecol 2002; 20: 51-56.

\section{SUPPORTING INFORMATION ON THE INTERNET}

The following supporting information may be found in the online version of this article:

Table S1 Characteristics of 556 singleton pregnancies with prenatal sonographic diagnosis of isolated mild or moderate ventriculomegaly (VM), according to whether associated anomaly was detected by prenatal MRI

Table S2 Characteristics of 556 singleton pregnancies with prenatal sonographic diagnosis of isolated mild or moderate ventriculomegaly (VM), according to whether associated anomaly was detected by postnatal MRI 
Papel de la resonancia magnética prenatal en fetos con ventriculomegalia aislada leve o moderada en la era de la neurosonografía: un estudio multicéntrico internacional

\section{RESUMEN}

Objetivos Evaluar el papel de la imagen por resonancia magnética (IRM) en la detección de anomalías asociadas en fetos que presentan ventriculomegalia aislada (VM) leve o moderada y que se someten a una evaluación ecográfica multiplanar del cerebro del feto.

Métodos Este fue un estudio multicéntrico, retrospectivo, de cohorte que incluyó a 15 centros especializados de medicina fetal en Italia, el Reino Unido y España. Los criterios de inclusión fueron los fetos afectados por una VM aislada leve (diámetro de la aurícula ventricular, 10,0-11,9 mm) o moderada (diámetro de la aurícula ventricular, 12,0-14.9 mm) como resultado de una ecografía, definida como VM con cariotipo normal y sin otras anomalías adicionales del sistema nervioso central (SNC) o del extra-sistema nervioso central (extra-SNC) en la ecografía, sometidos a una evaluación detallada del cerebro del feto mediante un enfoque multiplanar, tal como sugieren las directrices de la Sociedad Internacional de Ecografía en Obstetricia y Ginecología para la neurosonografía fetal, seguida de una imagen por resonancia magnética del feto. El resultado primario del estudio fue informar sobre la incidencia de anomalías adicionales del SNC, detectadas exclusivamente en la IRM prenatal ya que no fueron detectadas en la ecografía, mientras que el objetivo secundario fue estimar la frecuencia de anomalías adicionales detectadas exclusivamente después del nacimiento y que no fueron detectadas en las imágenes prenatales (ecografía y resonancia magnética). También se realizó un análisis de subgrupos en función de la edad gestacional en el momento de la IRM ( $<24$ vs $\geq 24$ semanas), la lateralidad de la VM (unilateral vs bilateral) y la gravedad de la dilatación (VM leve vs moderada).

Resultados En el análisis se incluyeron quinientos cincuenta y seis fetos con un diagnóstico prenatal de VM aislada leve o moderada en la ecografía. En el 5,4\% (IC 95\%, 3,8-7,6\%) de los casos se detectaron anomalías estructurales adicionales en la IRM prenatal que no se detectaron en la ecografía. Al considerar el tipo de anomalía, en la IRM se detectó hemorragia intracraneal supratentorial en el $26,7 \%$ de los fetos, mientras que la polimicrogiria y la lisencefalia se detectaron en el $20,0 \%$ y el $13,3 \%$ de los casos, respectivamente. La hipoplasia del cuerpo calloso se detectó en la resonancia magnética en el 6,7\% de los casos, mientras que la disgenesia se detectó en el 3,3\%. Los fetos con una anomalía asociada detectada tan sólo en la IRM tuvieron más probabilidades de tener una VM moderada que leve $(60,0 \%$ vs $17,7 \% ; \mathrm{P}<0.001)$, mientras que no hubo una diferencia significativa entre los dos grupos $(\mathrm{P}=0,2)$ en la proporción de casos con $\mathrm{VM}$ bilateral. El análisis de regresión logística mostró que un índice bajo de masa corporal materna (razón de momios ajustada (RMa), 0,85 (IC 95\%, 0,7-0,99); P=0,030), la presencia de VM moderada (RMa, 5,8 (IC 95\%, 2,6-13,4); $\mathrm{P}<0.001$ ), y la edad gestacional en la IRM $\geq 24$ semanas RMa, 4,1 (IC 95\%, $1,1-15,3) ; \mathrm{P}=0,038$ ) estuvieron asociadas de manera independiente a la probabilidad de detectar una anomalía asociada en la IRM. Las anomalías asociadas se detectaron exclusivamente al nacer y no fueron detectadas en las pruebas prenatales en el 3,8\% de los casos.

Conclusiones La frecuencia de una anomalía fetal asociada no detectada en la ecografía y tan sólo detectada en la IRM en los fetos con VM leve o moderada aislada que se someten a una neurosonografía es menor que la que se ha reportado anteriormente. La gran mayoría de estas anomalías son difíciles de detectar mediante ecografía. Los hallazgos de este estudio apoyan la práctica de la evaluación por IRM en todos los fetos con un diagnóstico prenatal de VM, aunque los padres pueden estar seguros de que cuando se detecta la VM en una neurosonografía el riesgo de una anomalía asociada es bajo.

\section{在神经超声检查的时代, 产前磁共振成像对有单纯性轻度或中度侧脑室扩张症胎儿的作用: 国际多中心研究}

\section{摘要}

目的对经多维超声评估胎脑的有单纯性轻度或中度侧脑室扩张症（VM）胎儿, 评估胎儿磁共振成像（MRI）在探测相关畸形上的作用。

方法这是一项由多中心参与的回顾性人群队列研究, 涉及意大利、英国和西班牙的15家转诊胎儿医学中心。研究入选标准为经超声检查 有单纯性轻度 (室房直径: 10.0-11.9毫米) 或中度 (室房直径: 12.0-14.9毫米) 侧脑室扩张症的胎儿, 被定义为超声检查有正常核型且无其它 附加的中枢神经系统 (CNS) 畸形或额外CNS畸形的VM, 并在胎儿MRI后采用关于胎儿超声波扫描图的国际妇产科超声学会指南所建议的多维方 法对胎脑进行了详细评估。本研究的主要结果是报告仅在产前MRI上探测出而未在超声检查中显示的附加CNS畸形发病率, 次要结果是评估仅在 产后发现而未从产前影像学检查（包括超声检查和MRI）中探测出的附加畸形发病率。研究还进行了以MRI检查时孕龄 (小于24周对比大于或等 于24周) 为依据的亚组分析, VM的功能偏侧化 (单侧对比双侧) 以及扩张的严重性（轻度VM与中度VM的对比）。

结果本研究分析中包含556例经产前超声检查诊断为有单纯性轻度或中度侧脑室扩张症的胎儿。在产前MRI中探测出而未在超声检查中显 示的附加结构性畸形在总病例中占 $5.4 \%(95 \% \mathrm{Cl}, 3.8-7.6 \%)$ 。相关畸形类型有: 经MRI检查在 $26.7 \%$ 的胎儿中探测到幕上频内出血, 又探测到 多小脑回和无脑回畸形分别占病例的 $20.0 \%$ 和 $13.3 \%$ 。经MRI检查, 在6.7\%的病例中探测到脑胼胝体发育不全, 而在3.3\%的病例中探测到发育不 全。相关畸形仅在MRI检查中探测出来的胎儿更有可能是患有中度而不是轻度VM（60.0\% vs $17.7 \%$; P $<0.001 ）$, 而两组之间有双侧VM的病例比 例却无显著差异 $(P=0.2)$ 。逻辑回归分析显示, 孕妇体重指数偏低（调整优势比（aOR）， $0.85(95 \% \mathrm{Cl}, 0.7-0.99) ; P=0.030 ）$ 、中度 VM的存在 $(a O R, 5.8(95 \% \mathrm{Cl}, 2.6$ - 13.4); $\mathrm{P}<0.001)$ 以及MRI检查时孕龄大于或等于 24 周（ $\mathrm{aOR}, 4.1(95 \% \mathrm{Cl}, 1.1$ - 15.3); $\mathrm{P}=0.038$ ） 与在MRI检查上探测到相关 畸形的可能性都分别存在着相关性。仅在出生时发现而未从产前影像学检查探测出的相关畸形占总病例的 $3.8 \%$ 。

结论针对患有单纯性轻度或中度侧脑室扩张症的胎儿, 仅在胎儿MRI检查中探测出而未在超声检查中显示的相关胎儿畸形发病率比以前 报告的要低。绝大多数这类畸形都难以从超声检查中探测出来。本研究的调查结果支持对产前诊断患有VM的每个胎儿采用MRI评估, 然而, 父 母可以放心, 当神经超声检查为单纯性VM 时, 相关畸形的风险较低。 